\title{
Subdivisão de formas livres em arquitetura com o objetivo de viabilização de sua fabricação: métodos e aplicações
}

\author{
Subdivision of free forms in architecture with the objective of making its \\ fabrication feasible: methods and applications \\ Subdivision de formes libres dans l'architecture, dans le but de permettre à sa \\ fabrication: méthodes et applications
}

\section{Subdivisión de las formas libres de la arquitectura con el objetivo de permitir su fabricación: métodos y aplicaciones}

Filipe Medeia de Campos $^{1}$

Gabriela Celani ${ }^{1}$

Recebido em 31/12/2016; revisado e aprovado em 19/04/2017; aceito em 30/04/2017

DOI: http://dx.doi.org/10.20435/inter.v18i3.1463

\begin{abstract}
Resumo: Este trabalho apresenta um panorama dos tipos de subdivisão de formas livres utilizados na arquitetura, bem como seus métodos e implementações computacionais, visando, especificamente, a sua aplicação para elementos de vedação. Foi realizada a revisão bibliográfica do assunto, bem como entrevista com especialista e exploração paramétrica dos métodos levantados em geometrias de teste. Desse modo, identificaram-se os principais de cada tipo de subdivisão, visando à viabilização de obras com formas livres, bem como questões de estética e acabamentos.
\end{abstract}

Palavras-chave: formas livres; subdivisão; modelagem paramétrica; fabricação digital; CAD-CAM.

Abstract: This work presents an overview of the types of subdivision of free forms used in the architecture, as well as their methods and computational implementations, specifically aiming their application to sealing elements. A bibliographic review of the subject was carried out, as well as a specialist interview and parametric exploration of the methods collected in selected geometries for testing. Through this approach, the main ones of each type of subdivision were identified, aiming at the viabilization of works with free forms, as well as aspects of aesthetics and finishes.

Key words: free forms; subdivision; parametric modeling; digital fabrication; CAD-CAM.

Résumé: Cet article présente un aperçu des types de subdivisant les formes libres utilisés dans l'architecture, ainsi que leur mise en œuvre et les méthodes de calcul visant spécifiquement son application à des éléments d'étanchéité. II a effectué une revue de la littérature du sujet, ainsi que des entretiens avec des experts et l'exploitation des méthodes paramétriques soulevées dans des géométries de test. Ainsi, nous avons identifié la clé de chaque type de subdivision, visant à permettre aux œuvres de formes libres, ainsi que l'esthétique et les finitions problèmes.

Mots-clés: formes libres; subdivision; modélisation paramétrique; fabrication numérique; CAD-CAM.

Resumen: Este artículo presenta una visión general de los tipos de la subdivisión de las formas libres utilizados en arquitectura, así como sus implementaciones y métodos computacionales dirigidas específicamente su aplicación a elementos de sellado. Se realizó una revisión de la literatura sobre el tema, así como entrevistas con expertos y explotación de los métodos paramétricos planteadas en geometrías de prueba. Por lo tanto, hemos identificado la clave de cada tipo de subdivisión, destinada a permitir obras con formas libres, así como la estética y acabados cuestiones.

Palabras clave: formas libres; subdivión; modelado paramétrico; fabricación digital; CAD-CAM.

\footnotetext{
${ }^{1}$ Universidade Estadual de Campinas (UNICAMP), Campinas, São Paulo, Brasil.
} 


\section{INTRODUÇÃO}

Nas últimas décadas, incorporaram-se ferramentas de Computer Aided Design (CAD) e Computer Aided Manufacturing (CAM) no ramo de arquitetura, permitindo ao arquiteto utilizar espaços geométricos e formas livres que, até pouco tempo atrás, eram de difícil produção com técnicas industriais (KOLAREVIC, 2005; BURRY; BURRY, 2010). Por formas livres, podemos entender as formas geradas através da modelagem Non-uniform rational b-spline (NURBS) ou a partir de superfícies regradas, usualmente apresentando dupla curvatura (POTTMANN et al., 2007).

Essas formas já eram utilizadas antes do surgimento do computador. Alguns exemplos são o edifício do Instituo Oceanográfico de Valência, de Félix Candela, as abóbadas, em igrejas e templos, e as formas criadas pelo arquiteto Antoni Gaudí, que utilizava um método de projeto analógico similar à modelagem NURBS, que lhe permitiu criar obras arquitetônicas com formas livres de grande complexidade. A partir dos anos 1960, o surgimento da tecnologia CAD permitiu a disseminação e maior facilidade no uso e modelagem dessas formas, facilitando sua representação e propiciando a automatização de sua produção.

No que diz respeito à materialização das formas livres com equipamentos de fabricação digital, existem duas abordagens: produzir o edifício inteiro de uma só vez, em geral por meio de impressão 3D (processo aditivo), ou subdividi-lo em partes menores, que, em geral, são produzidas por processos subtrativos e/ou de conformação, tendo em vista as limitações dimensionais desses equipamentos em relação à escala do edifício (Figura 1).

\section{Materialização de formas livres}
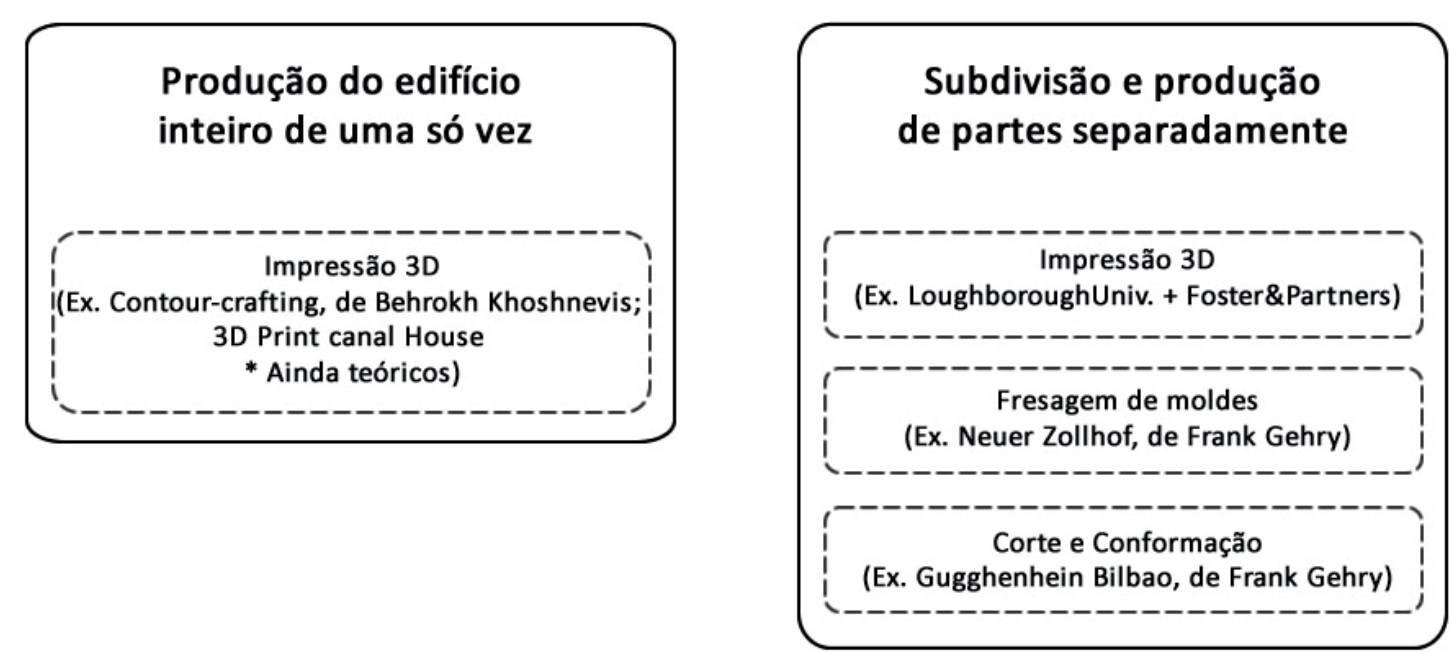

Figura 1 - Abordagens de materialização de formas livres com fabricação digital Fonte: dos autores

Desde 2014, empresas e grupos de pesquisa vêm utilizando impressoras 3D de concreto para construir a estrutura e a vedação de casas e pequenos edifícios (HAGER; GOLONKA; PUTANOWICZ, 2016), demonstrando que é possível utilizar essa tecnologia na construção civil. Contudo ela ainda apresenta diversas limitações, tais como materiais (utilizando somente o concreto ou plástico) e escala (HAGER; GOLONKA; PUTANOWICZ, 2016). Além disso, houve poucos testes dessa tecnologia com formas livres. A maior parte das aplicações se destinou à produção de esculturas e peças de design, sendo ainda necessário explorá-la. 
Desse modo, a subdivisão da forma é atualmente a abordagem mais utilizada, consistindo em dividir uma forma em componentes menores, que possam ser transportados ou produzidos in loco com equipamentos aditivos, subtrativos ou de conformação. Existem diversos tipos de subdivisões com diferentes características, diferenciando-se pela curvatura do elemento resultante, quantidade de divisões, número de vértices e outros fatores. A escolha pelo tipo de subdivisão e seu resultado final são influenciados por fatores como intenção do arquiteto e questões estéticas até por questões estruturais ou de materiais.

No que diz respeito à estrutura, deve-se levar em conta sua relação com a subdivisão da forma, sendo que a estrutura pode ou não ser gerada independentemente dessa subdivisão. Quando a estrutura é independente, é necessário somente identificar os pontos de conexão entre esta e a fachada, como ocorre no edifício Selfridge, projetado pelo escritório Future Systems. No caso de a estrutura ser gerada por essa subdivisão, é necessário levar em conta os fatores estruturais no processo de geração da malha de subdivisão, tal como ocorre no edifício Swiss RE, pelo escritório Fosters \& Partners e Arup.

Quanto aos materiais construtivos, estes vão determinar diversas características da subdivisão e produção, tais como as tecnologias de produção, dimensões máximas das placas, curvatura máxima, tipo de superfície, dentre outros. No caso do concreto, as fôrmas costumam ser produzidas em fresadoras CNC de três ou cinco eixos, no caso de forma livre em geral (CANEPARO, 2014), e por corte com fio quente, no caso de formas regradas ou de curvatura simples (CUTLER; WHITING, 2007), sendo a segunda opção mais barata.

Existem também os materiais laminares, em que a espessura é desprezível, se comparada às demais dimensões. Entre eles, podemos citar o vidro, painéis laminados compostos, chapas metálicas e chapas de madeira (como compensado), os quais, em sua maioria, podem ser cortados em fresadoras CNC (CANEPARO, 2014) e depois conformados. Contudo existem outros aspectos que devem ser levados em conta, como a flexibilidade do material, a curvatura das chapas, as conexões entre bordas e conexões nos vértices das faces. Estes fatores estão todos interligados, sendo importante analisar questões estéticas, de custos, de manutenção e outras, visando ao melhor resultado final. No caso, por exemplo, do painel de vidro, este é consideravelmente mais barato se utilizado plano (CUTLER, 2007), porém pode prejudicar a sensação de fluidez da forma.

O método de subdivisão de formas livres já era utilizado há muito tempo, antes do advento do computador. A técnica de subdividir geometricamente estruturas em pedra para esculpir manualmente suas partes era conhecida desde o Egito antigo. A ciência da estereotomia, contudo, se desenvolveu entre a segunda metade do século XVI e o início do século XVIII (TREVISAN, 2011). Como, a partir do início do século XX, o uso da pedra como elemento estrutural caiu em desuso, em função da dificuldade de industrialização e do custo da mão de obra, existe atualmente um desconhecimento por parte dos arquitetos em geral sobre essas técnicas. Contudo, com a popularização dos equipamentos de fabricação digital, em especial subtrativos, que possibilitam o trabalho preciso em 3-dimensões a partir de modelos geométricos digitais, muitos estudos estão sendo realizados sobre o assunto, envolvendo diversos materiais, técnicas, tecnologias e novas soluções, inclusive explorando as limitações e novos usos das tecnologias de fabricação digital². Como as escolhas de projeto devem se fundamentar pelas questões de estética, funcionalida-

\footnotetext{
${ }^{2}$ Um exemplo disto é o projeto Digital Stereotomy, do Block Research Group (BRG) do Institute of Technology in Architecture da ETH Zurich (http://block.arch.ethz.ch/brg/research/digital-stereotomy).
} 
de, custo, produção, montagem, utilização e intenção do arquiteto, faz-se fundamental que se compreenda os métodos de materialização de formas livres e suas influências no resultado final.

Este artigo apresenta uma revisão da literatura sobre os principais métodos de subdivisão de formas livres, visando a sua materialização em arquitetura. Com o crescente interesse e utilização desse tipo de geometria por parte dos arquitetos, faz-se necessário desenvolver e divulgar o conhecimento que permita sua produção com qualidade. Este trabalho se concentra nos elementos de vedação, considerando a estrutura como sendo gerada independentemente. Além disso, serão enfatizados os materiais laminados, por sua grande utilização na arquitetura contemporânea. Em termos metodológicos, o artigo adota a abordagem de revisão bibliográfica, com entrevista com especialista na área e exploração dos tipos de subdivisões levantados, aplicados em geometrias de teste de modo paramétrico.

\section{MÉTODOS E CARACTERÍSTICAS DOS TIPOS DE SUBDIVISÃO}

Existem diversos métodos de subdivisão de superfícies, sendo que, neste trabalho, eles serão classificados de acordo com o número de lados das superfícies resultantes (Figura 2), quais sejam: a triangulação, a subdivisão por quadriláteros e a subdivisão por polígonos de cinco ou mais lados. Cada um desses tipos de subdivisão apresenta diferentes características no que diz respeito à curvatura das superfícies, à complexidade dos encaixes e aos ângulos entre as placas. Dentro de cada tipo, existem diferentes métodos para obterem-se as malhas subdivididas, bem como técnicas de modificação destas e de alteração de um tipo de malha para outro.

Subdivisão de superfícies

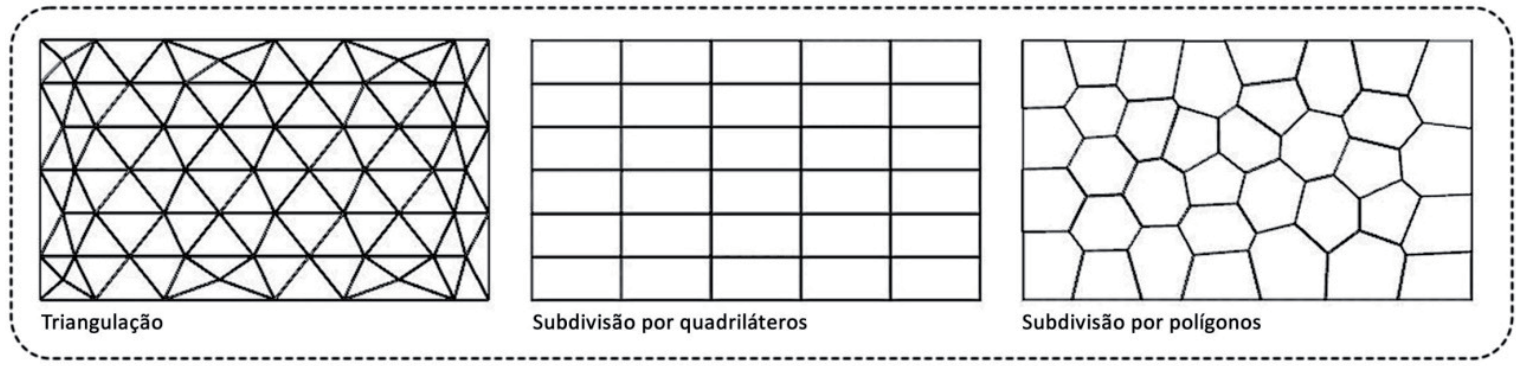

Figura 2 - Classificação de métodos de subdivisão de superfícies

Fonte: dos autores

\subsection{Triangulação}

Dentre os métodos de subdivisão, a triangulação é a utilizada há mais tempo no meio computacional, com os primeiros artigos sobre o desenvolvimento de malhas de Bélzier na década de 70 e seu primeiro uso comercial na década de 90, na indústria de animação, com a Pixar (POTTMANN et al, 2007). Atualmente, é muito usada nos meios computacionais para animação, renderização, cálculos de iluminação e ganho térmico, análises de esforços e outros cálculos e representações gráficas diversas, além de ser importante para o uso de algumas tecnologias de CAM, através de arquivos como de esterolitografia (.STL), muito usado em fresadoras CNC e impressoras 3D.

Esse tipo de subdivisão é amplamente utilizado principalmente por garantir que a face gerada será sempre plana. Embora seja possível obter triângulos não-euclidianos (não planos), 
esse tipo de figura não é utilizado na triangulação, por gerar faces que podem ter dupla curvatura, além de outros problemas.

Durante muitos anos, na arquitetura, a triangulação foi preferida para a subdivisão de superfícies livres por causa de limitações tecnológicas e do alto custo do processo de se produzir vidros e materiais laminados de dupla curvatura, permitindo utilizar somente placas planas. Segundo o arquiteto Neil Katz ${ }^{3}$, se, por um lado, elimina-se o problema de utilizar peças curvas, por outro, geram-se outros problemas a serem solucionados, como encaixes e acabamentos.

A fixação dos elementos de vedação sobre a estrutura pode-se dar ao longo de suas arestas ou em seus vértices. Ao se subdividir uma superfície livre em elementos planos, as placas adjacentes nem sempre estarão sobre o mesmo plano.

No caso de fixação ao longo das arestas, os ângulos entre as placas variam, costumando ser diferentes de $180^{\circ}$ (Figura 3). Tendo em vista essa variação, nem sempre se podem utilizar elementos-padrão de conexão entre as arestas das placas, sendo necessário produzir elementos personalizados para cada encontro. Dependendo da abrangência dessa variação, pode ser mais vantajoso utilizar elementos de conexão flexíveis (Figura 4), desde que a precisão da angulação das placas não dependa destes elementos.
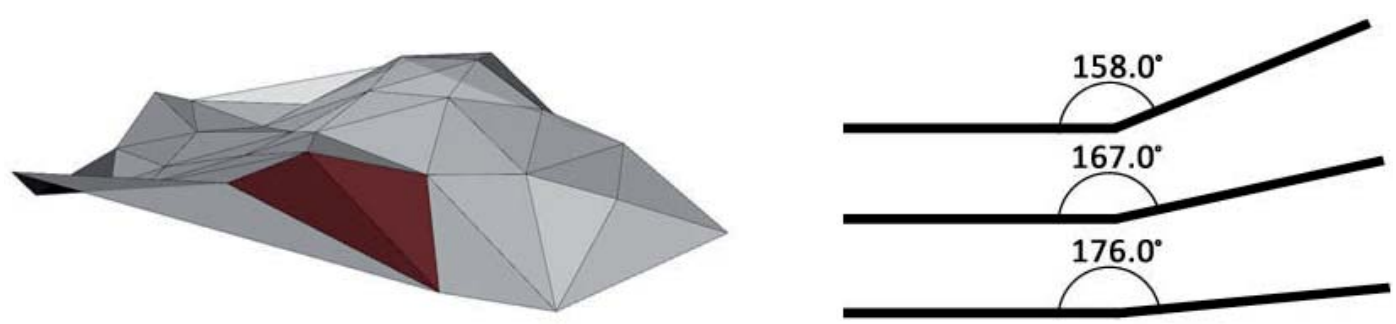

Figura 3 - Exemplo de variação do ângulo entre placas adjacentes na triangulação Fonte: dos autores

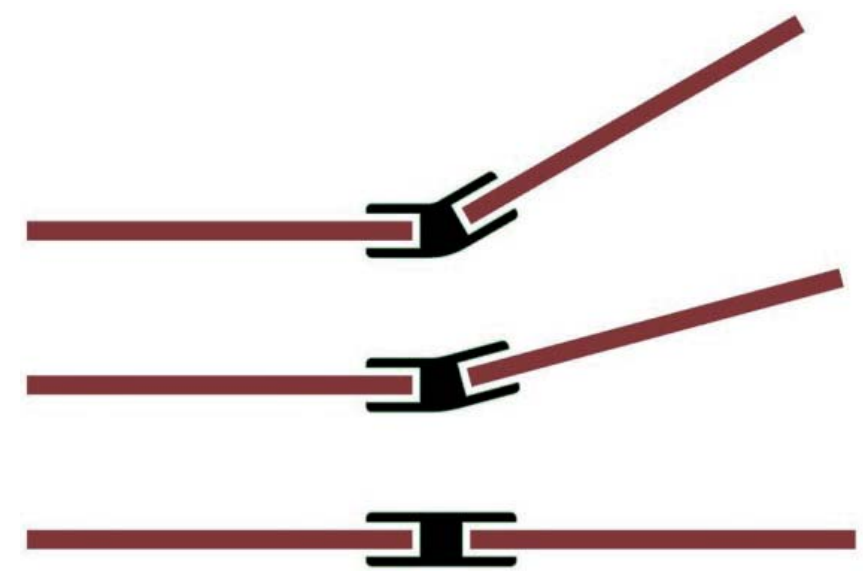

Figura 4 - Uso de conector flexível para união e vedação de placas

Fonte: dos autores

\footnotetext{
${ }^{3}$ Entrevista concedida pelo arquiteto Neil Katz, do escritório de arquitetura SOM, Chicago (EUA), a Filipe Campos, em 12/03/2016.
} 
No caso de fixação nos vértices, os ângulos também variam, sendo que, nesse caso, faz-se necessário o uso de elementos personalizados rígidos para cada vértice (Figura 5). Outro problema desse ponto de encontro de placas é a quantidade de elementos por vértice. Caso essa quantidade seja muito grande (superior a oito), o elemento de conexão se tornará muito complexo e, portanto, de maior custo.

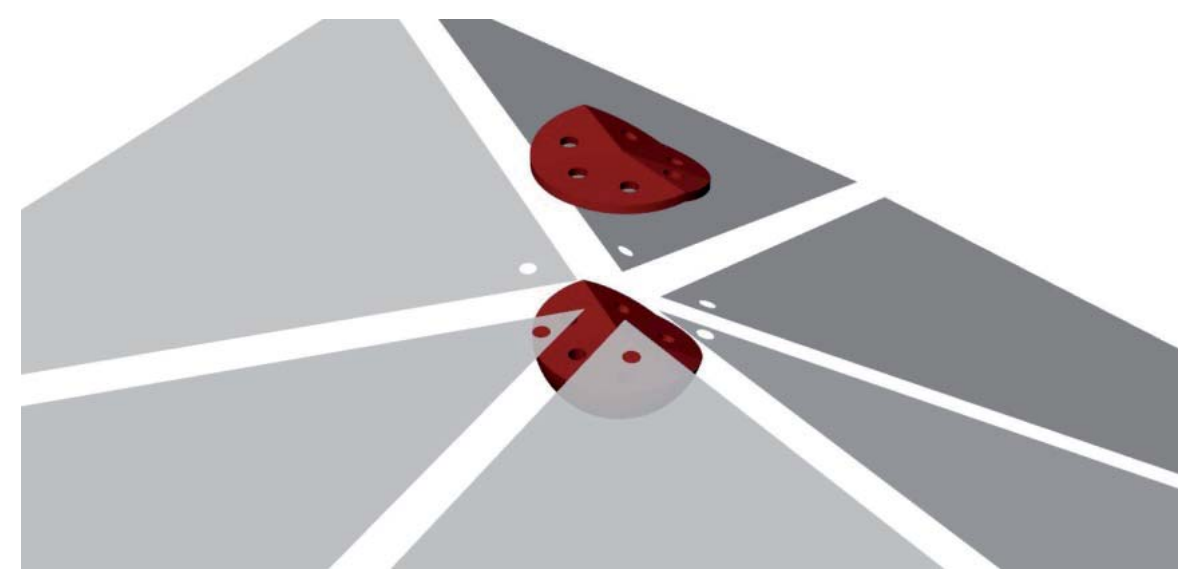

Figura $\mathbf{5}$ - Exemplo de fixação nos vértices em placas triangulares Fonte: dos autores

Outro problema comum na utilização de placas triangulares é a presença de quinas com ângulos mais fechados, criando áreas frágeis. "Dependendo do material e destes ângulos, podem ocorrer danos às peças no transporte e manuseio nas áreas frágeis", aponta Neil Katz ${ }^{4}$, do escritório SOM. Obviamente esse problema pode ocorrer em qualquer peça com ângulos agudos, independentemente do tipo de subdivisão, porém ele é mais comum em faces triangulares.

Além dessas questões técnicas, existem também as referentes à estética e à intenção do arquiteto. Nesse caso, o tipo de triangulação utilizada e as operações de modificação de malha são de extrema importância. Os tipos mais comuns de triangulação são por quadriláteros, de Delaunay, por bolhas e por polígonos diversos (POTTMANN et al., 2007; SHIMADA; GOSSARD, 1995). Podemos citar como modificadores de malha o colapso e a subdivisão de triângulos (WELCH; WITKIN, 1994).

A triangulação por quadriláteros se baseia em primeiro subdividir a superfície em quadriláteros de forma regular, inserindo depois uma diagonal, dividindo cada quadrilátero em dois triângulos (POTTMANN et al., 2007). Alguns autores chamam esse processo de operação de subdivisão por quadriláteros, sendo que Welch o nomeia de "change" (WELCH; WITKIN, 1994). Dentro desse método, a obtenção dos quadriláteros pode ser feita pelo método isoparamétrico ou pela geração automática de "mesh".

Os quadriláteros isoparamétricos são obtidos a partir de curvas isoparamétricas e têm como resultado uma malha de divisão regular (POTTMANN et al., 2007), sendo, posteriormente, divididos por suas diagonais (Figura 6). Esse método funciona bem em superfícies com quatro ou três bordas (neste caso, se considera que são quatro, sendo uma de comprimento igual a zero), não sendo aconselhado para superfícies com mais bordas ou com aberturas (trimmed surface).

\footnotetext{
${ }^{4}$ Entrevista concedida pelo arquiteto Neil Katz, do escritório de arquitetura SOM, Chicago (EUA), a Filipe Campos, em 12/03/2016.
} 

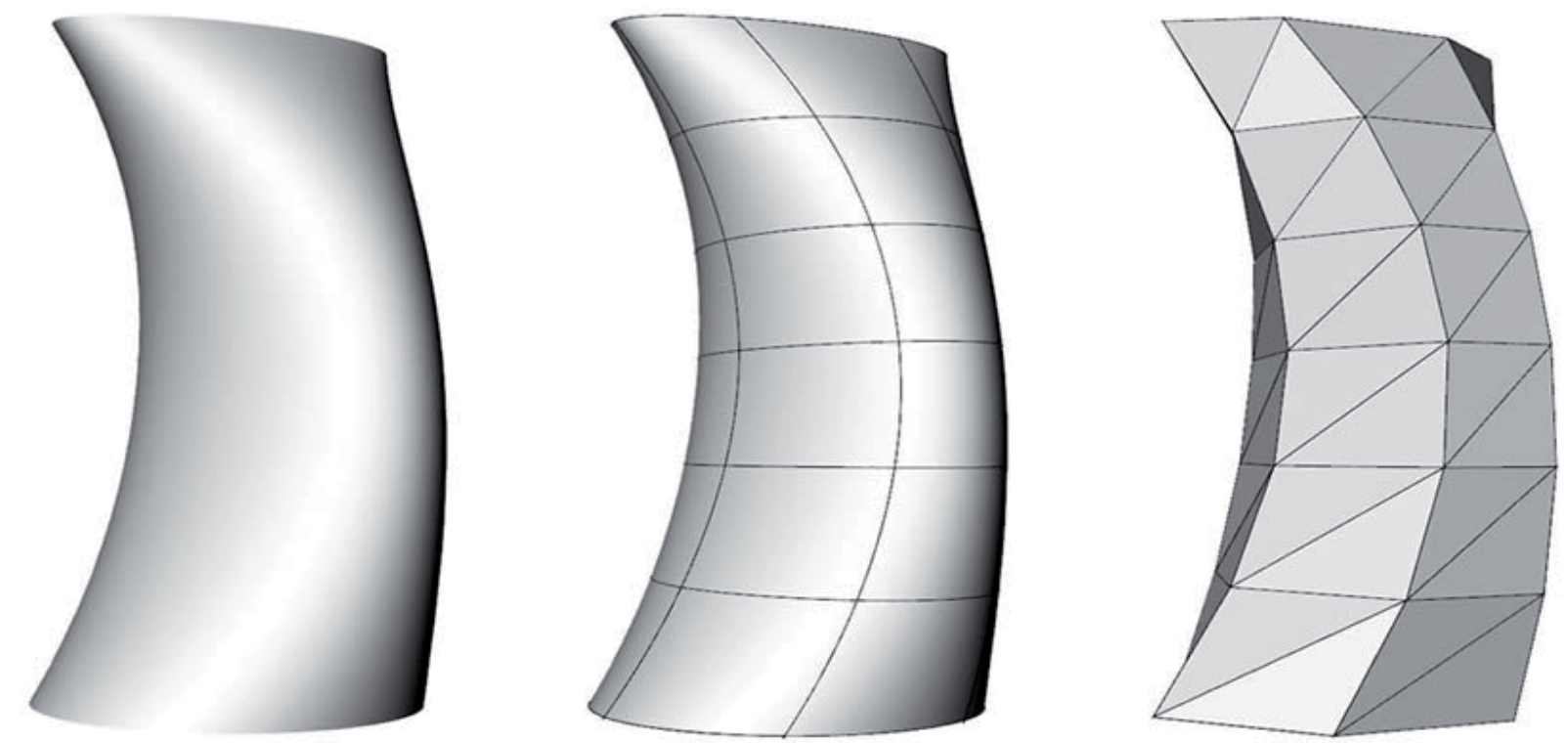

Figura 6 - Triangulação isoparamétrica

Fonte: dos autores

Já o outro método se baseia em um comando comum em softwares de modelagem NURBS, conhecido como mesh, o qual subdivide a superfície em triângulos e quadriláteros (com ou sem dupla curvatura) em dimensões relativamente regulares (Figura 7). Esse método tem como vantagem sua aplicação a qualquer tipo de superfície (independentemente do número de arestas ou da presença de aberturas) (Figura 8).
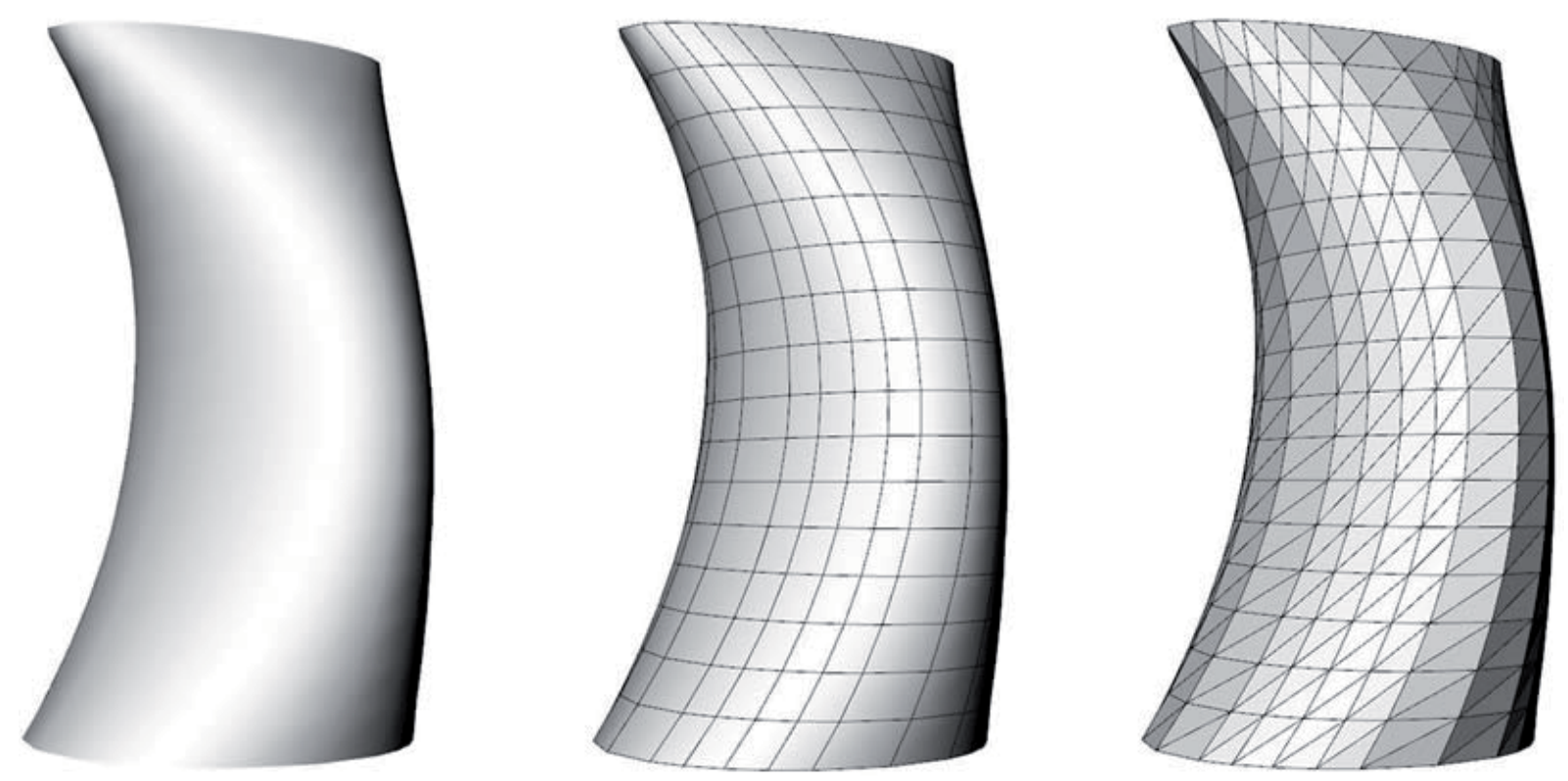

Figura 7 - Triangulação por mesh

Fonte: dos autores 

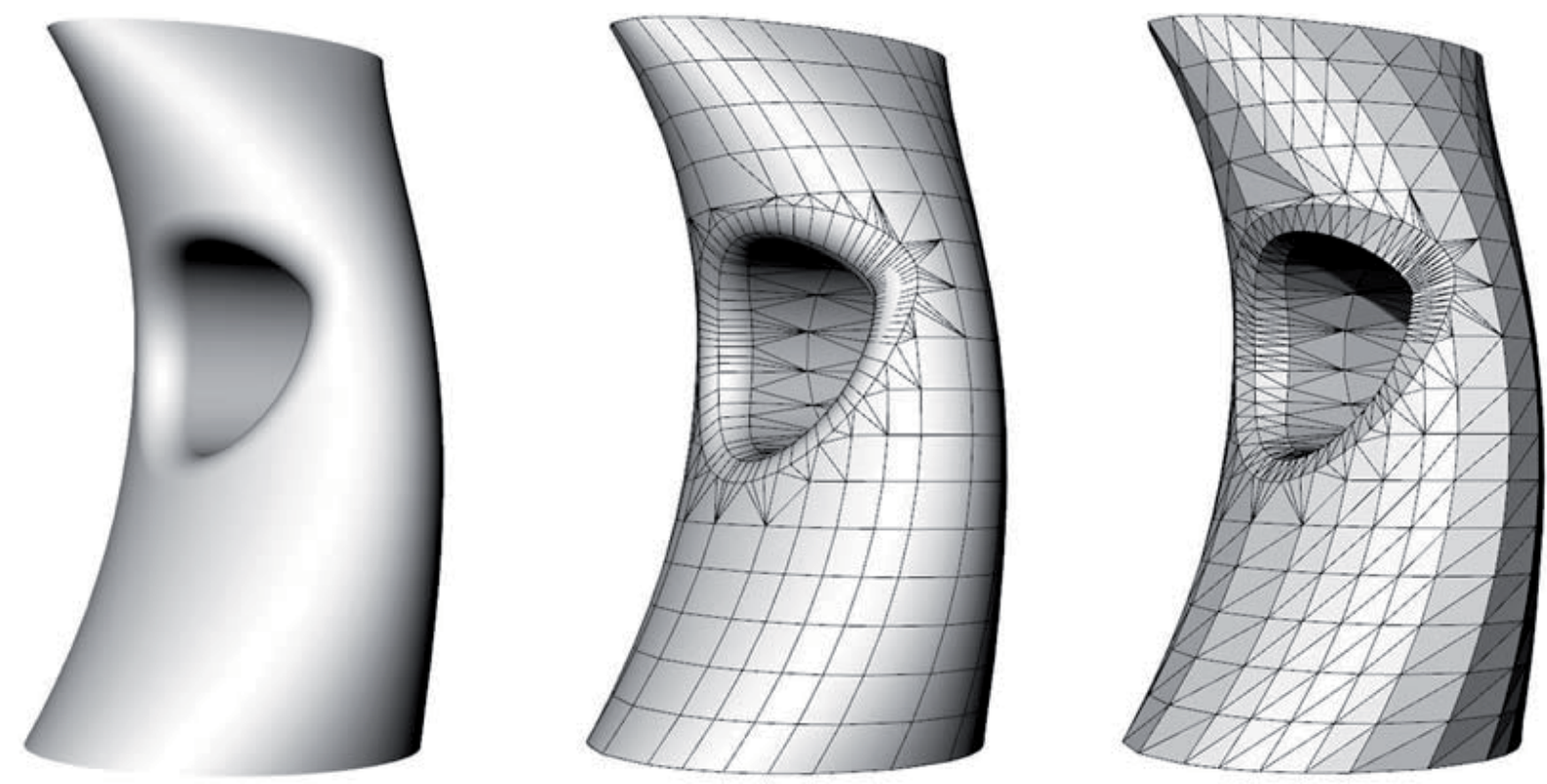

Figura 8 - Triangulação por mesh em superfície com aberturas Fonte: dos autores

A triangulação de Delaunay utiliza pontos localizados no espaço tridimensional, na qual seu algoritmo de triangulação consiste em conectar cada ponto aos mais próximos de forma aleatória, sendo que as arestas são analisadas quanto aos ângulos que criam (POTTMANN et al., 2007; BERG et al., 2008). Normalmente, a triangulação de Delaunay é implementada de modo aleatório e incremental, buscando a solução com maior número de ângulos mínimos (POTTMANN et al., 2007; BERG et al., 2008). Esse método foi criado para se obter a representação topográfica virtual de uma superfície real, sendo que a regularidade desse método depende da distribuição dos pontos obtidos no levantamento. Apesar de sua clara aplicação em levantamentos e digitalização de superfícies físicas, alguns autores buscam sua utilização na arquitetura. Esse uso, contudo, pode gerar malhas com ângulos fechados ou elementos alongados (onde uma dimensão é muito superior às demais) (SHIMADA; GOSSARD, 1995), não sendo aconselhado seu uso nesses casos.

O terceiro método, de triangulação por bolhas, busca obter arestas de dimensão similar (SHIMADA; GOSSARD, 1995). Nesse método, primeiro se efetua uma divisão isoparamétrica da superfície, obtendo os pontos que serão os centros das esferas, sendo que o raio dessas esferas está relacionado à distância com o centro das esferas vizinhas. A distribuição dessas esferas passa por um processo de relaxamento de malha, levando em conta as forças de atração e repulsão entre esferas. Quando se chega numa distribuição na qual a irregularidade da dimensão das arestas está dentro de um fator considerado bom, é utilizado o diagrama de Voronoi, tendo como pontos os centros das esferas, e conectado o centro de cada célula aos seus vértices (SHIMADA; GOSSARD, 1995). Esse processo gera triângulos relativamente regulares e uma malha, normalmente, irregular (Figura 9). Para a aplicação em arquitetura, esse método é um dos mais adequados de triangulação. 

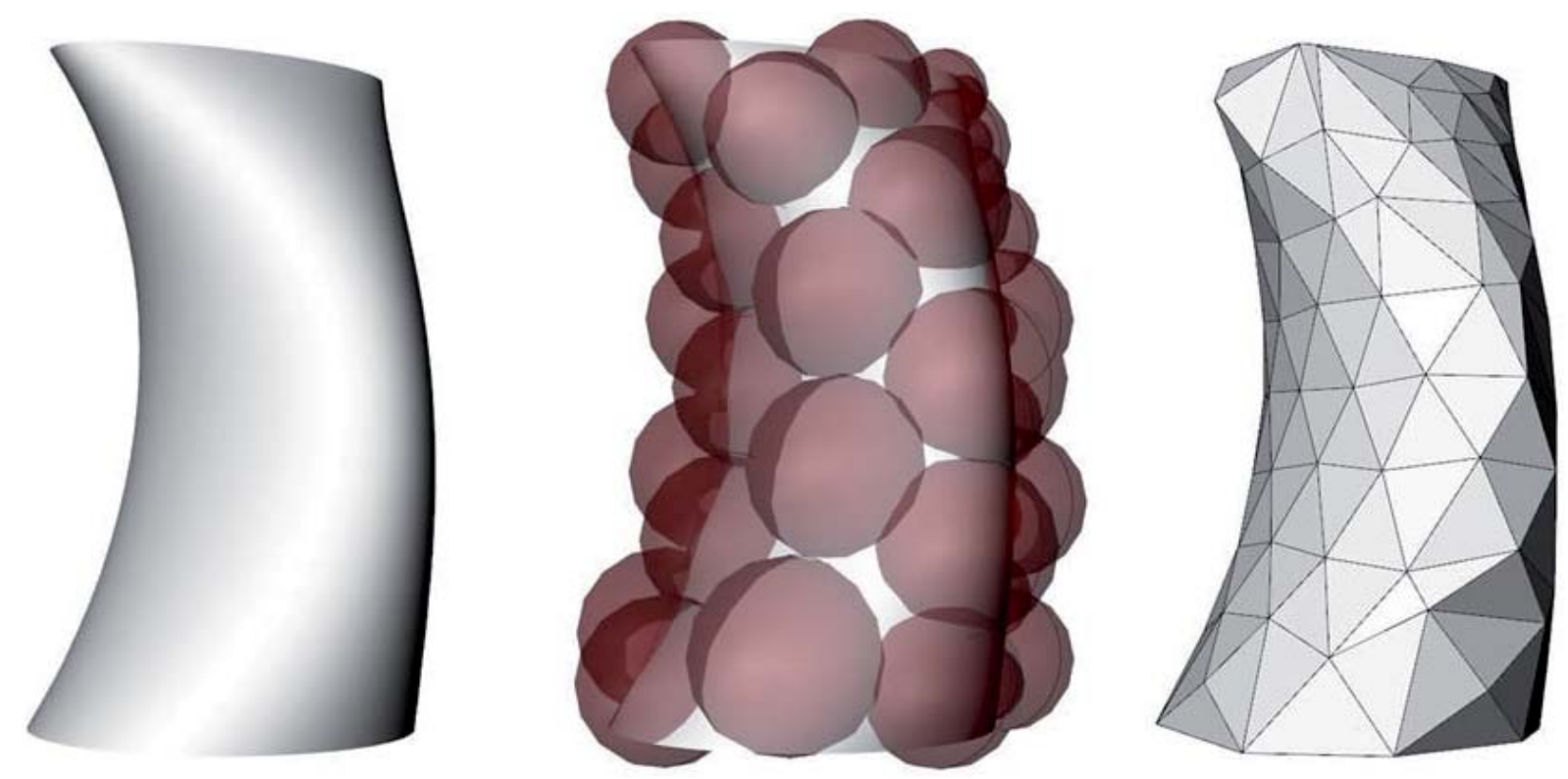

Figura 9 - Triangulação por bolhas

Fonte: dos autores

O último método, que consiste na triangulação por polígonos diversos, tem como princípio a aplicação de qualquer polígono na superfície, onde cada um tem seus vértices ligados ao seu centro, gerando a superfície triangulada (POTTMANN et al., 2007). Esse método abrange, na realidade, diversos métodos mais particulares, variando o tipo de polígono aplicado. Normalmente, existem dois tipos de aplicação que são muito utilizados: projeção e intersecção tridimensional. A projeção se baseia em fazer uma distribuição de polígonos em um plano e projetá-los sobre a superfície que se pretende subdividir (Figura 10), enquanto a intersecção tridimensional se baseia em distribuir poliedros na superfície e encontrar a intersecção entre eles, num processo similar à triangulação por bolhas. A regularidade da malha resultante e a sua aplicação prática em arquitetura variam de acordo com o polígono usado e a forma de aplicação.
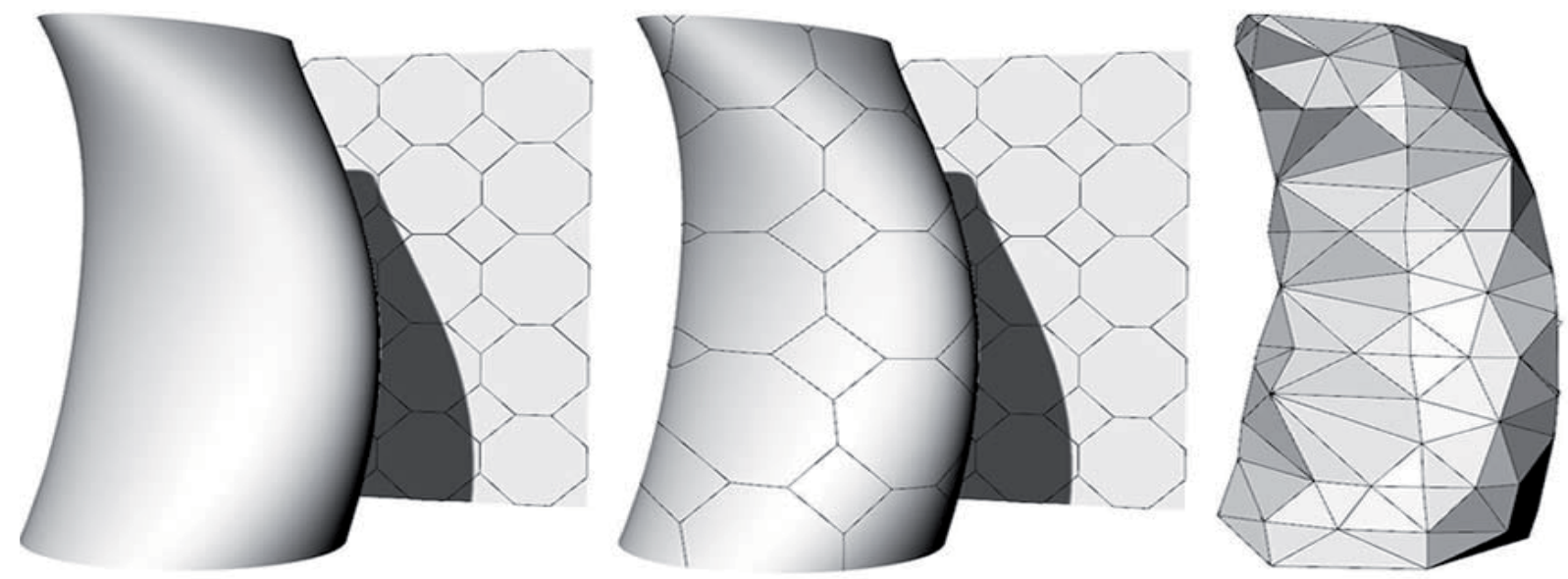

Figura 10 - Triangulação por polígonos projetados

Fonte: dos autores 
Independentemente do método utilizado, existem formas de se alterar a malha triangular, sendo que as duas principais operações são a divisão e o colapso de triângulos (WELCH; WITKIN, 1994). Na divisão, se cria um ponto central em uma das arestas do triângulo, que em seguida é conectado com o vértice oposto, dividindo o triângulo em dois (Figura 11). No colapso, é selecionada uma aresta a ser removida, sendo selecionados os triângulos vizinhos, gerando uma forma poligonal. As retas internas são eliminadas e encontra-se, então, o ponto central desse polígono, conectando-o aos vértices do polígono, reduzindo o número de triângulos (Figura 12) (WELCH; WITKIN, 1994). Essas operações costumam ser utilizadas para padronizar as dimensões das faces triangulares, subdividindo triângulos grandes ou distribuindo a área de triângulos pequenos entre seus adjacentes.
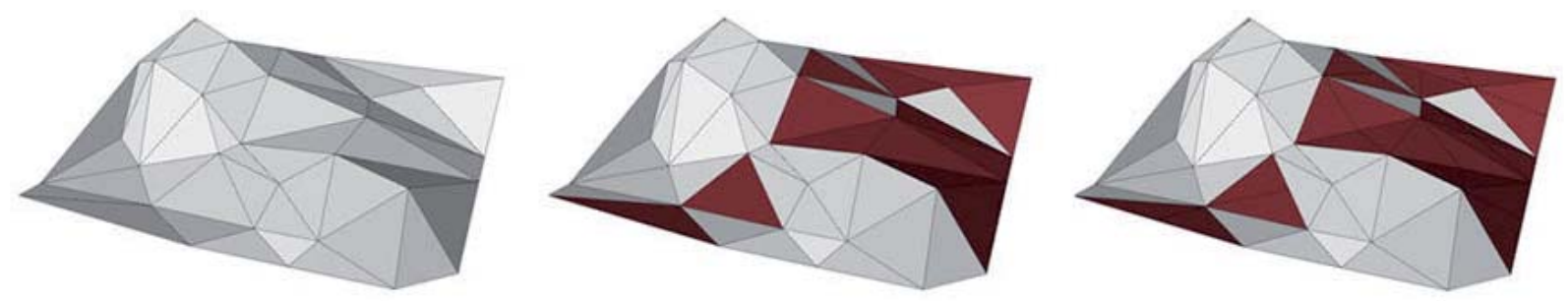

Figura 11 - Divisão de triângulos

Fonte: dos autores
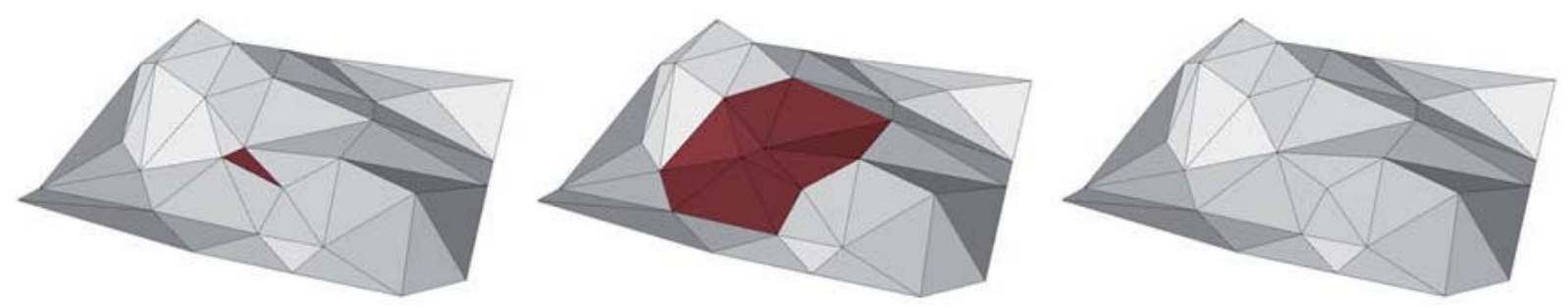

Figura 12 - Colapso de triângulos

Fonte: dos autores

\subsection{Subdivisão por quadriláteros}

Ao contrário da triangulação, a subdivisão por quadriláteros não busca garantir que as faces sejam planas, normalmente seguindo a curvatura da forma original (POTTMANN et al., 2007). Por esse fato, esse método não costuma ter uma grande gama de utilizações fora da arquitetura, sendo o seu principal uso a materialização de fachadas de edifícios. Ao se utilizar faces curvas (seja ou não de dupla curvatura) cria-se a sensação de fluidez entre as peças, mantendo questões estéticas e funcionais que podem ser imprescindíveis à experiência arquitetônica pretendida pelo arquiteto.

Por manter a forma original, as faces resultantes podem ser planas, de curvatura simples ou de dupla curvatura, requerendo diferentes estratégias para sua produção. Os elementos de curvatura simples são, por definição, desenvolvíveis, ou seja, podem ser planificados (POTTMANN et al., 2007), enquanto os elementos de dupla curvatura não são planificáveis, devendo ser deformados plasticamente para adequarem-se à forma desejada. Dependendo do tipo de material e suas características, essa curvatura pode ser obtida a frio ou a quente. 
O método a quente necessita de equipamentos especializados, sendo realizado somente nas fábricas que produzem estes materiais. Já o método a frio não depende do aquecimento do elemento, em alguns casos podendo ser realizado in loco. $\mathrm{O}$ arquiteto Neil Katz ${ }^{5}$ aponta que, no caso do vidro, é possível curvá-lo das duas maneiras, sendo que o método a frio restringe-se a curvaturas muito pequenas, mas pode ser efetuado em obra e é mais econômico que o método a quente.

No que diz respeito às junções das bordas ou vértices das faces, estas se encontram no mesmo plano (Figura 13), criando uma superfície contínua. Pelo fato de as bordas estarem no mesmo plano, torna-se possível utilizar elementos-padrão, rígidos ou flexíveis. Se compararmos o número de arestas entre um modelo triangulado e um modelo subdividido por quadriláteros, o segundo apresentará um menor número total de bordas, requerendo menos material de conexão (POTTMANN; SCHIFTNER; WALLNER, 2008).
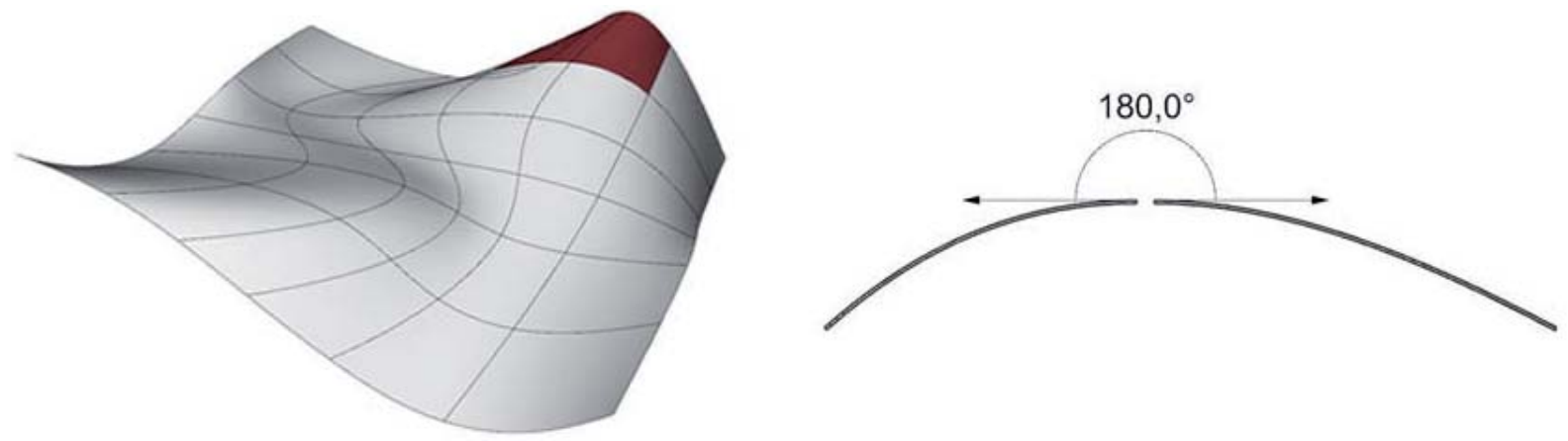

Figura 13 - Demonstração de encontro entre placas adjacentes, com ângulo de tangentes igual a $180^{\circ}$

Fonte: dos autores

Para cada vértice, suas faces adjacentes apresentam concordância, estando no mesmo plano nesse ponto, permitindo que o elemento de fixação no vértice seja plano. Além disso, o número de elementos por vértice tende a ser menor (sendo o ideal quatro elementos por vértice), reduzindo assim a complexidade da peça (Figura 14).

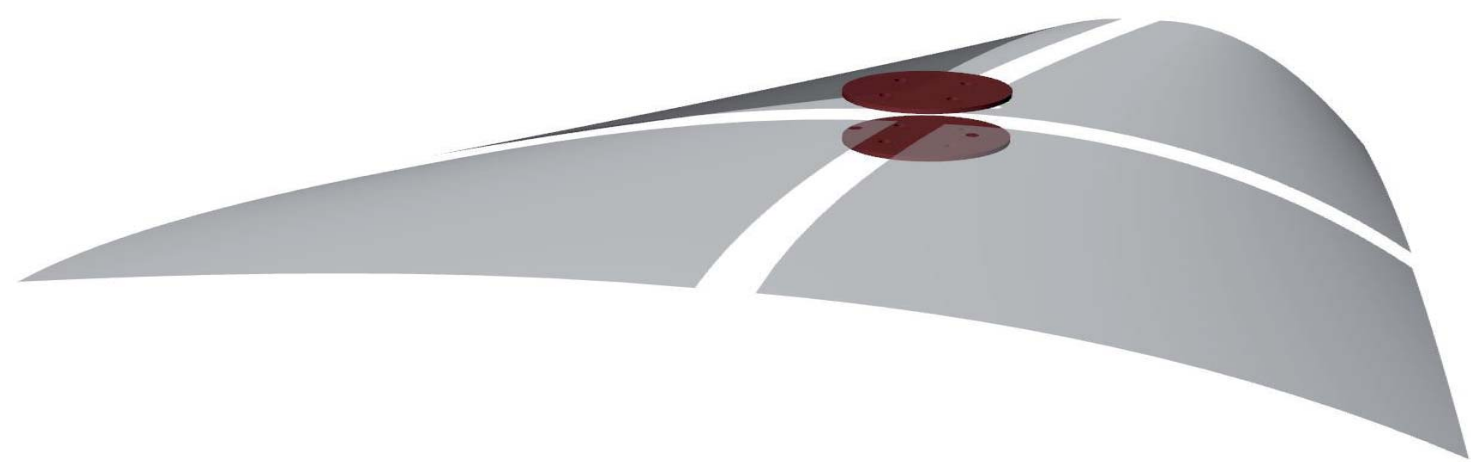

Figura 14 - Exemplo de elemento de fixação plano

Fonte: dos autores

${ }^{5}$ Entrevista concedida pelo arquiteto Neil Katz, do escritório de arquitetura SOM, Chicago (EUA), a Filipe Campos, em 12/03/2016. 
Quanto aos métodos de subdivisão por quadriláteros, os principais são: divisão isoparamétrica, por divisão em faixas desenvolvíveis, por divisão em faixas regradas e colapso de polígonos (POTTMANN; SCHIFTNER; WALLNER, 2008; WANG, 2013). É importante reforçar que os métodos descritos não podem, necessariamente, ser aplicados a qualquer superfície nem garantem a geração de uma malha regular (WANG, 2013). Nesse caso, podemos citar como modificador de malha a subdivisão de quadriláteros.

A divisão isoparamétrica, como já citada, baseia-se em subdividir uma superfície através de linhas isoparamétricas, sendo uma divisão regular (POTTMANN et al., 2007). Alguns autores apontam que essa técnica costuma gerar uma malha simples e bem solucionada, podendo ser utilizada como ponto de partida. Posteriormente, pode ser necessário refiná-la por meio de subdivisões (POTTMANN; SCHIFTNER; WALLNER, 2008; WANG, 2013).

A subdivisão por faixas desenvolvíveis tem como objetivo criar faces de curvatura simples, permitindo que sejam planificadas. De modo geral, a superfície é dividida isoparametricamente em um sentido, criando faixas (d-strip model), as quais são analisadas quanto à sua curvatura. As faixas que possuem dupla curvatura são reconstruídas a partir de suas bordas, gerando uma face curva desenvolvível (Figura 15) (POTTMANN; SCHIFTNER; WALLNER, 2008). Essas faixas são então divididas no outro sentido, gerando os quadriláteros desenvolvíveis.
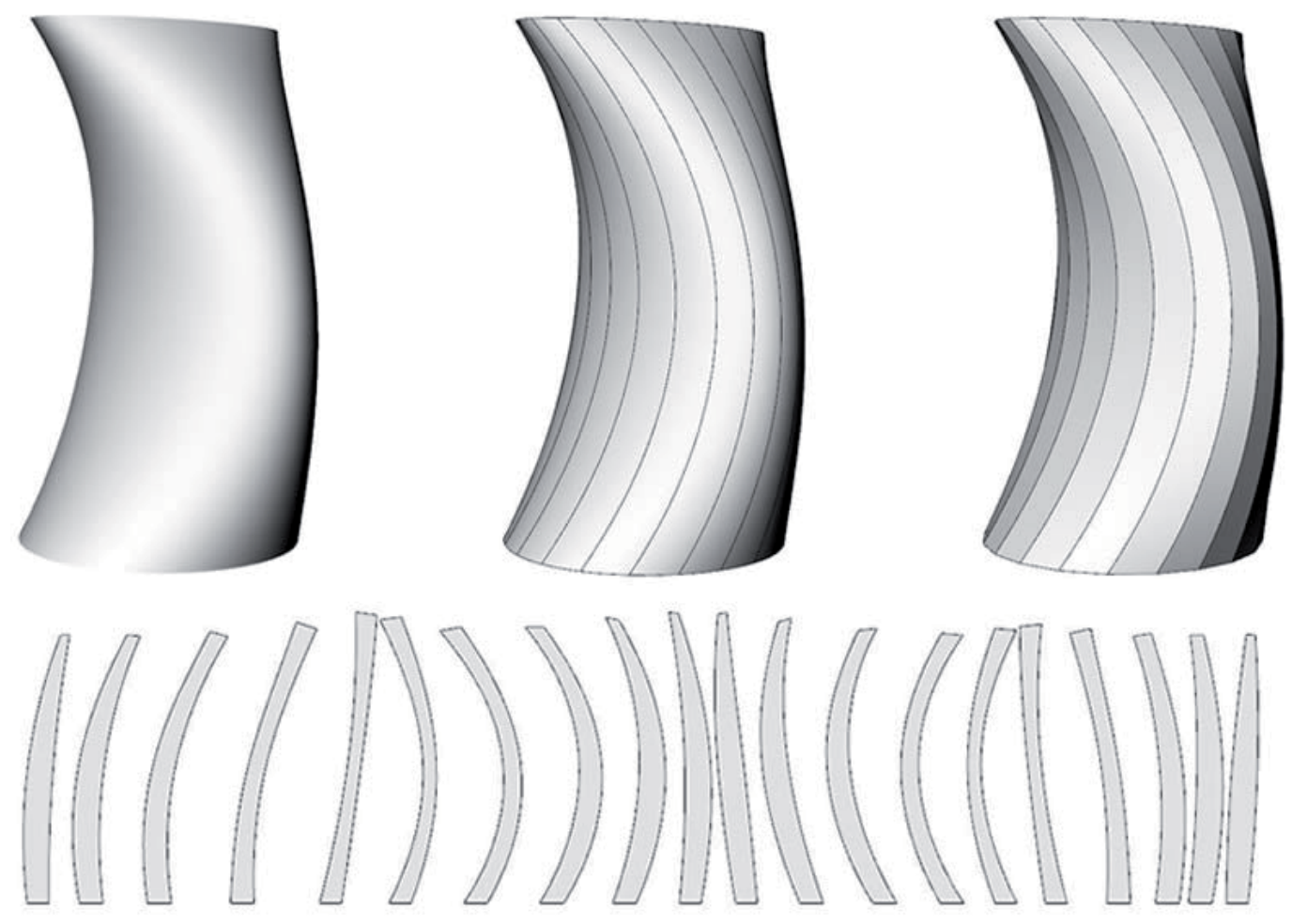

Figura 15 - Subdivisão por faixas desenvolvíveis Fonte: dos autores

Outro modo similar é a divisão por faixas regradas. Novamente, há a subdivisão da superfície em faixas isoparamétricas, porém as bordas das faces que correspondem às bordas da superfície original que foram seccionadas são substituídas por retas (POTTMANN; SCHIFTNER; WALLNER, 2008). Através do processo de varredura (sweep), são criadas superfícies regradas, as quais são subdivididas no outro sentido para gerar os quadriláteros (Figura 16). Para simplificação, podem-se 
seguir somente as curvas de menor curvatura (POTTMANN; SCHIFTNER; WALLNER, 2008). Esse processo pode ser utilizado tanto para placas curvadas a frio quanto para fôrmas de concreto, as quais podem ser produzidas em isopor por corte por fio quente. Tanto nesse método quanto no por faixas desenvolvíveis, a aproximação entre a forma resultante e a forma original estará relacionada à quantidade de subdivisões.
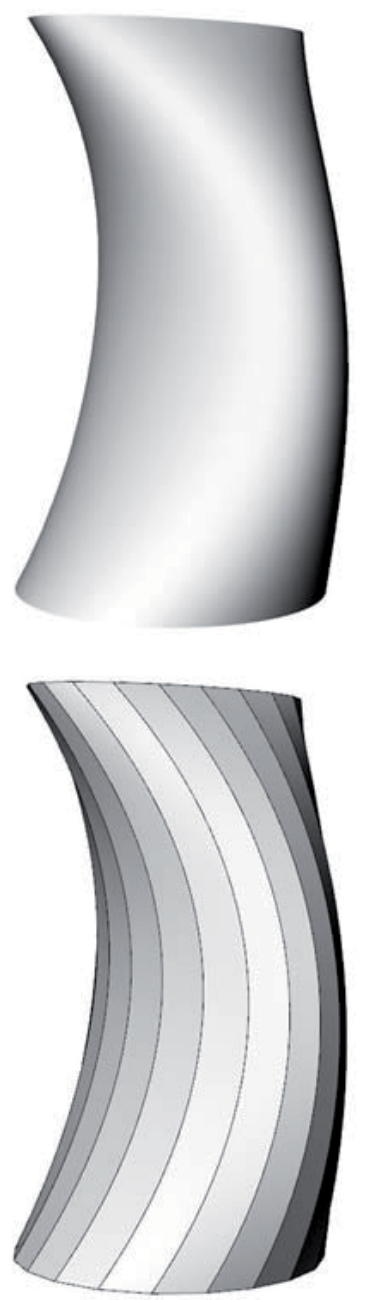
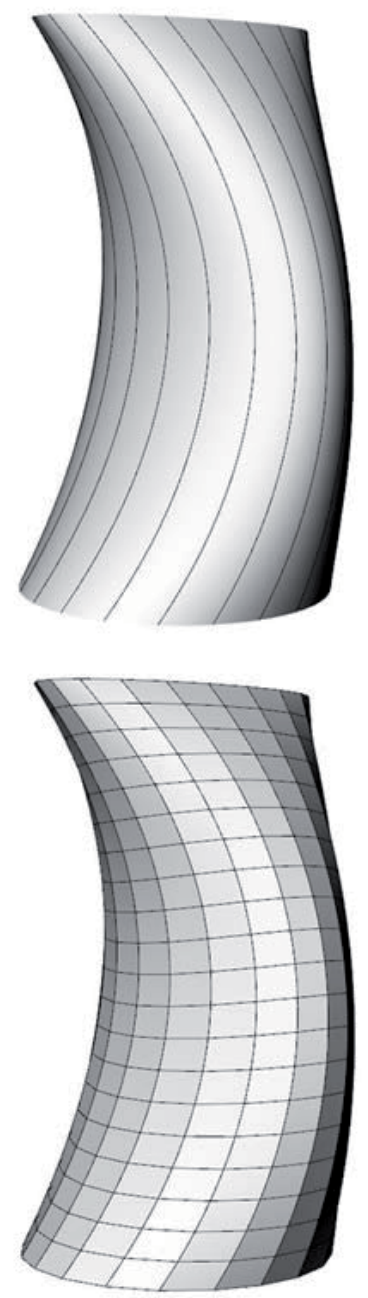
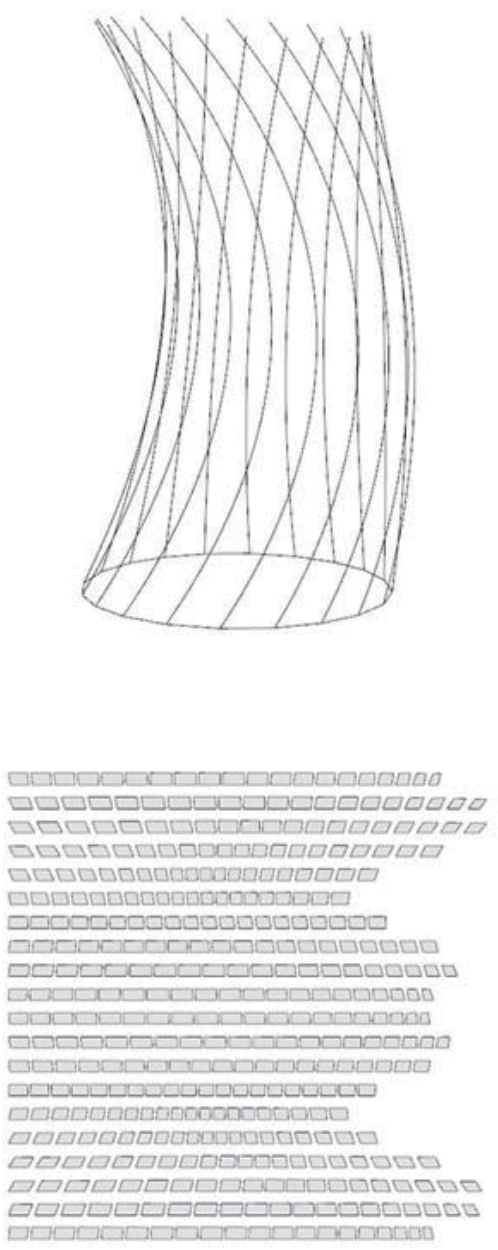

Figura 16 - Subdivisão por faixas regradas

Fonte: dos autores

O método de colapso de polígonos, dentro da subdivisão por quadriláteros, é o único que necessita de uma malha inicial para ser aplicado, pois se baseia em subdividir os polígonos iniciais em quadriláteros. Para cada face da malha, é localizado o seu centro de massa, conectando-o aos pontos médios das bordas desse polígono, gerando quadriláteros irregulares (Figura 17) (WANG, 2013; POTTMANN et al., 2007). 

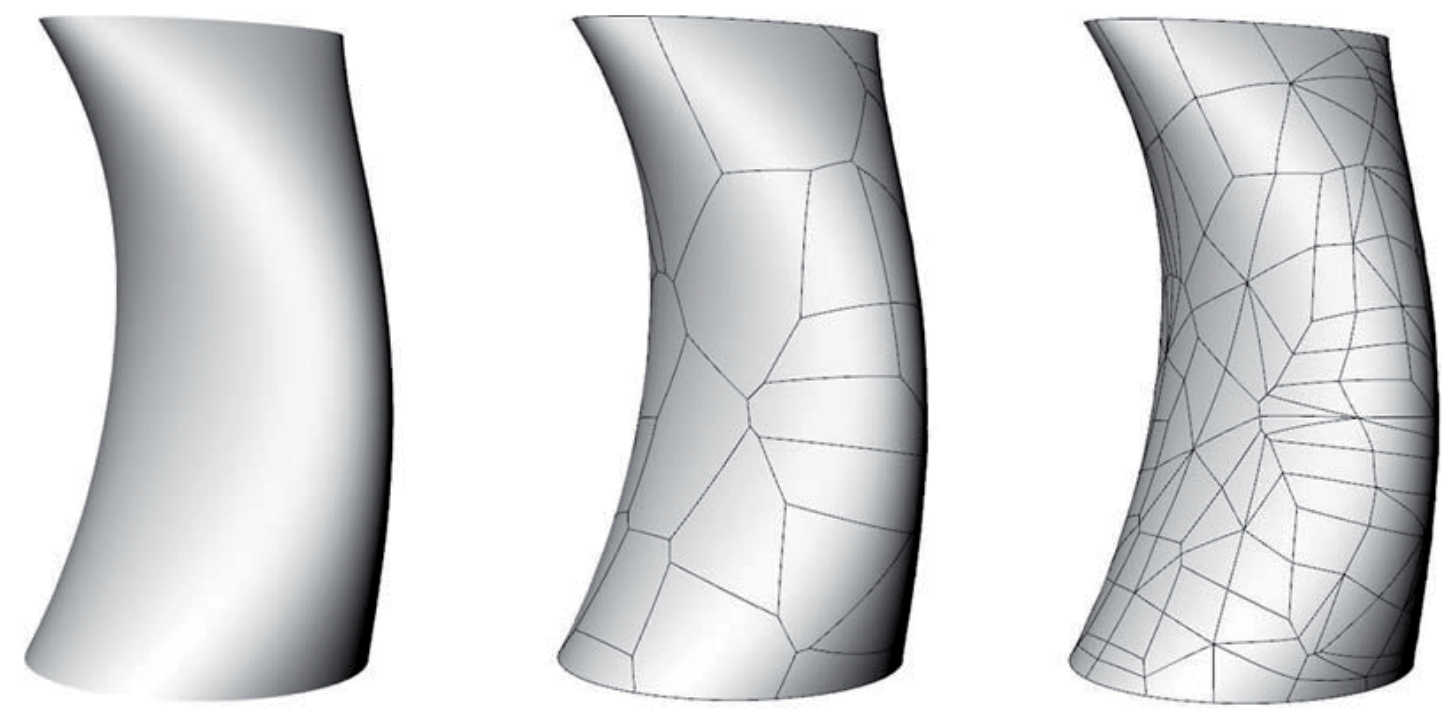

Figura 17 - Geração de malha quadrilátera por colapso de polígonos Fonte: dos autores

A modificação de malha através da subdivisão de quadriláteros funciona de modo similar à divisão isoparamétrica, dividindo os quadriláteros selecionados isoparametricamente em quatro. Esse tipo de subdivisão é muito utilizado caso haja quadriláteros que ultrapassem as dimensões máximas para a produção e transporte, subdividindo-os sem que haja necessidade de alterar toda a malha (Figura 18).
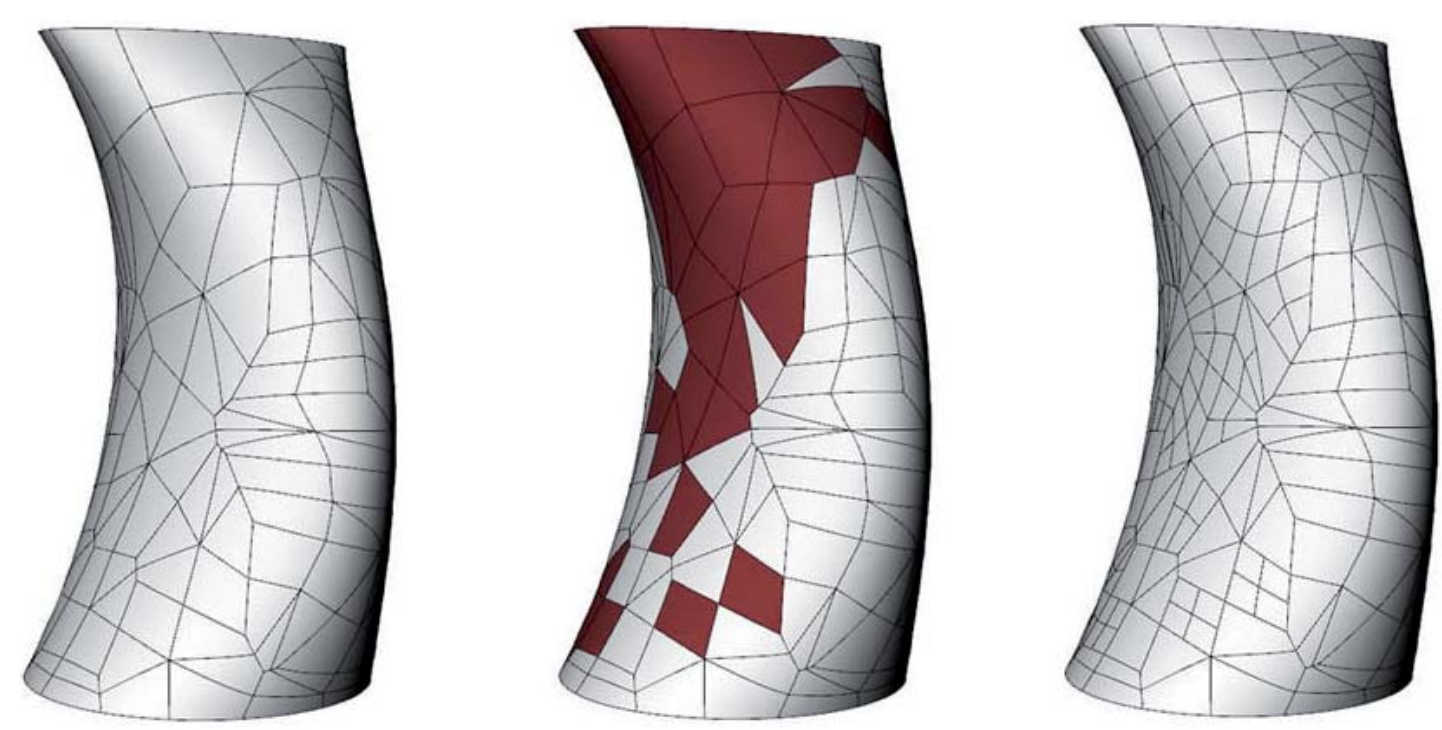

Figura 18 - Subdivisão de quadriláteros cuja área excede o valor máximo de fabricação Fonte: dos autores

\subsection{Subdivisão por polígonos}

A subdivisão por polígonos de cinco ou mais lados pode ser considerada uma categoria mais genérica, pois compreende diversas formas poligonais, gerando malhas que podem ou não ser regulares. Nesse tipo de subdivisão, é comum que cada vértice tenha somente três elementos de vedação adjacentes, reduzindo a complexidade do elemento de fixação no vértice (CUTLER; 
WHITING, 2007). Segundo Neil Katz ${ }^{6}$, normalmente consegue-se malhas cujos polígonos têm, majoritariamente, ângulos obtusos, reduzindo a chance de danos às peças no transporte e manuseio.

No que diz respeito à curvatura das faces, esta pode variar entre plana, de curvatura simples ou dupla, dependendo do método utilizado. Quanto às fixações por bordas ou vértices e quanto à produção das placas, suas características e problemas seguem os mesmos já citados anteriormente por tipo de curvatura das faces. Logo, faces planas terão os mesmo problemas citados na seção de triangulação, enquanto as faces com curvatura simples ou dupla, os citados na subdivisão por quadriláteros.

De modo geral, existem três métodos para se realizar esse tipo de subdivisão: por planos tangentes, por poliedros e por projeção. Destes, o primeiro é o único que visa à geração de faces planas.

O método dos planos tangentes, utilizado por Cuttler, baseia-se em determinar pontos da forma original, que servem de base para gerar planos tangentes à forma, sendo que os planos são interseccionados um pelo outro, gerando faces planas (CUTTLER; WHITING, 2007). Apesar de gerar faces planas, a forma resultante distancia-se da original, e seu uso nem sempre é adequado para aplicações em arquitetura.

O método por poliedros baseia-se em distribuí-los pela superfície, seja de forma regular ou não, criando a subdivisão pela intersecção entre a superfície e esses poliedros. A forma e as dimensões de cada poliedro podem ser sensíveis às mudanças topológicas e topográficas da superfície, além de se utilizar de relações de vizinhança para modificar a malha (HANSMEYER; DILLENBURGER, 2013). Esse método pode englobar o uso do diagrama de Voronoi 3D (Figura 19) e de hexágonos (Figura 20), que são muito utilizados em arquitetura.
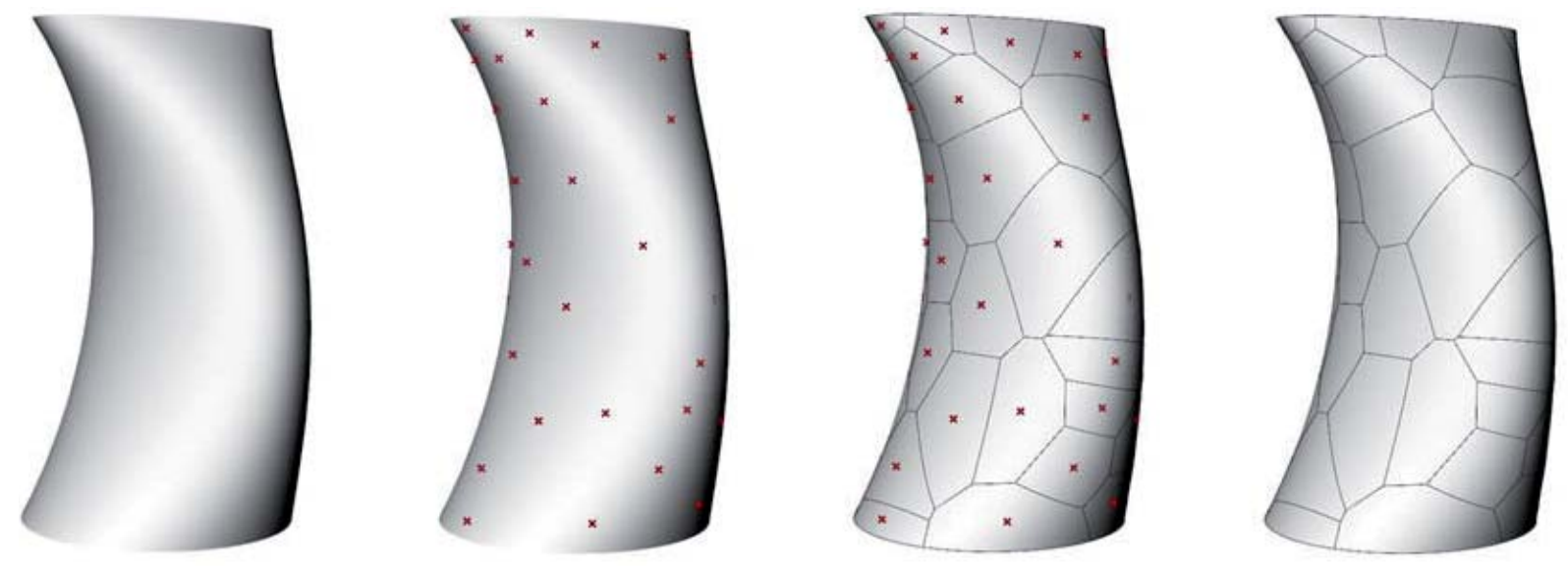

Figura 19 - Subdivisão por Diagrama de Voronoi 3D

Fonte: dos autores

\footnotetext{
${ }^{6}$ Entrevista concedida pelo arquiteto Neil Katz, do escritório de arquitetura SOM, Chicago (EUA), a Filipe Campos, em 12/03/2016.
} 

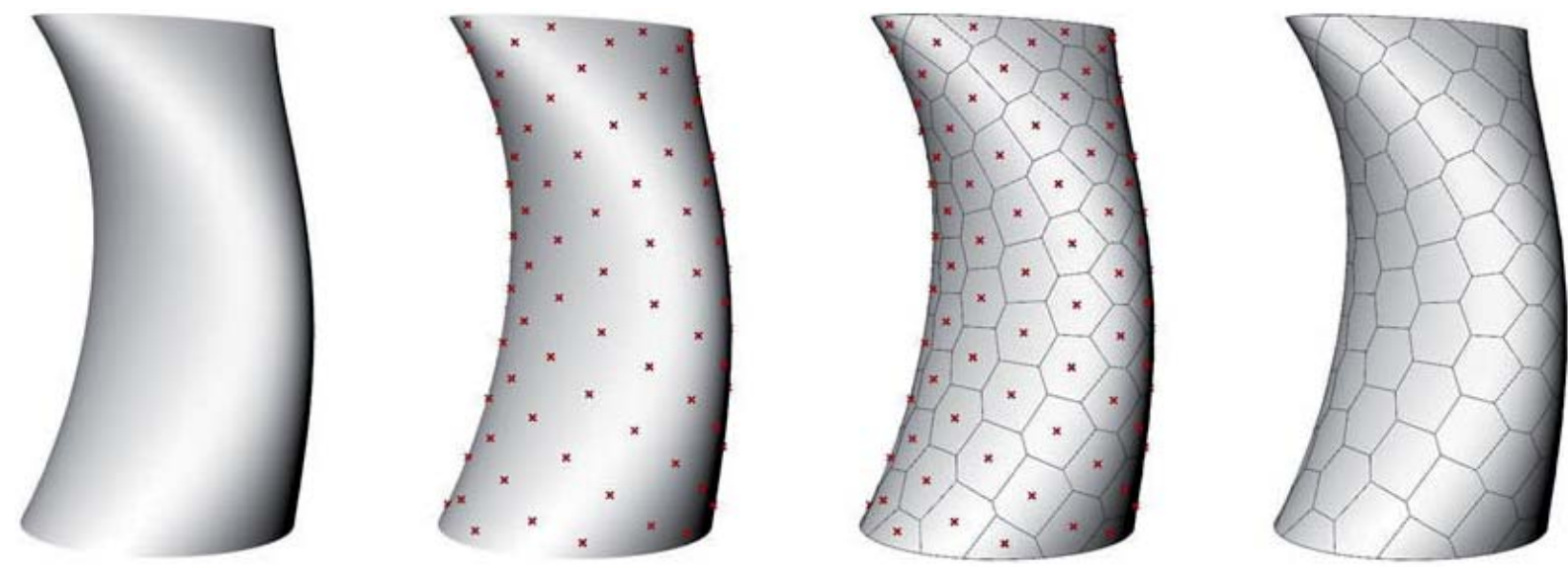

Figura 20 - Subdivisão por hexágonos

Fonte: dos autores

Enquanto os outros métodos subdividem diretamente a forma original, o método de projeção subdivide uma superfície plana, a qual é projetada posteriormente na forma original. Nesse processo, podem ocorrer deformações da malha, resultando em faces desconexas, com dimensões discrepantes e ângulos muito fechados, o que não é aconselhado para qualquer tipo de forma.

\subsection{Relaxamento de malha}

Ao se efetuar a subdivisão de uma superfície, a regularidade das faces criadas varia de acordo com os métodos usados e a forma da superfície original. Nem sempre se consegue o resultado desejado, mas existem métodos para melhorar a regularidade da malha, sendo o mais comum o relaxamento de malha. Este tem como princípio melhorar a malha em termos estéticos (POTTMANN et al., 2007), porém também pode influenciar outros aspectos, regularizando as dimensões dos elementos de vedação e dos elementos estruturais.

Existem diversos métodos de relaxamento de malhas, sendo que o mais utilizado é o algoritmo de Lloyd, que se baseia em mover os vértices das faces de acordo com os centros de gravidade destas (SURAZHSKY; ALLIENZ; GOTSMAN, 2003). Esse método de se baseia no diagrama de Voronoi. O primeiro diagrama é gerando a partir dos pontos iniciais, em seguida é encontrado o centroide dessas células, e um novo diagrama é gerado, tendo os centroides como ponto de partida. Esse procedimento é repetido recursivamente até obter-se uma malha mais regular (Figura 21). 

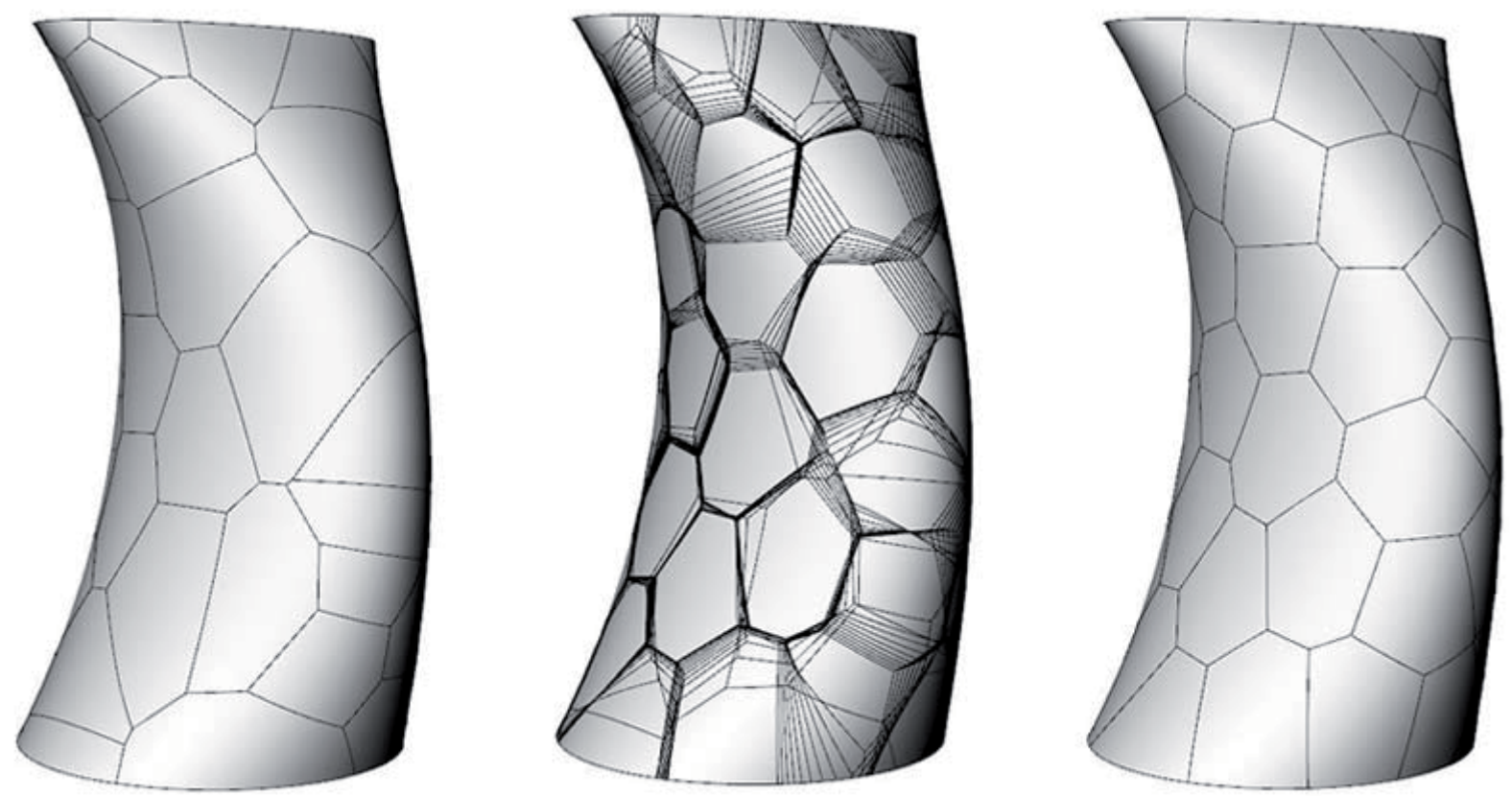

Figura 21 - Relaxamento de malha baseada no diagrama de Voronoi Fonte: dos autores

\subsection{Transformação de malha}

Como já apontado, é possível efetuar operações de modificação da malha, subdividindo faces específicas ou reduzindo seu número. Do mesmo modo, é possível transformar uma malha em outro tipo (Figura 22), através de operações como triangulação de polígonos ou colapso de triângulos, como demonstrado anteriormente.

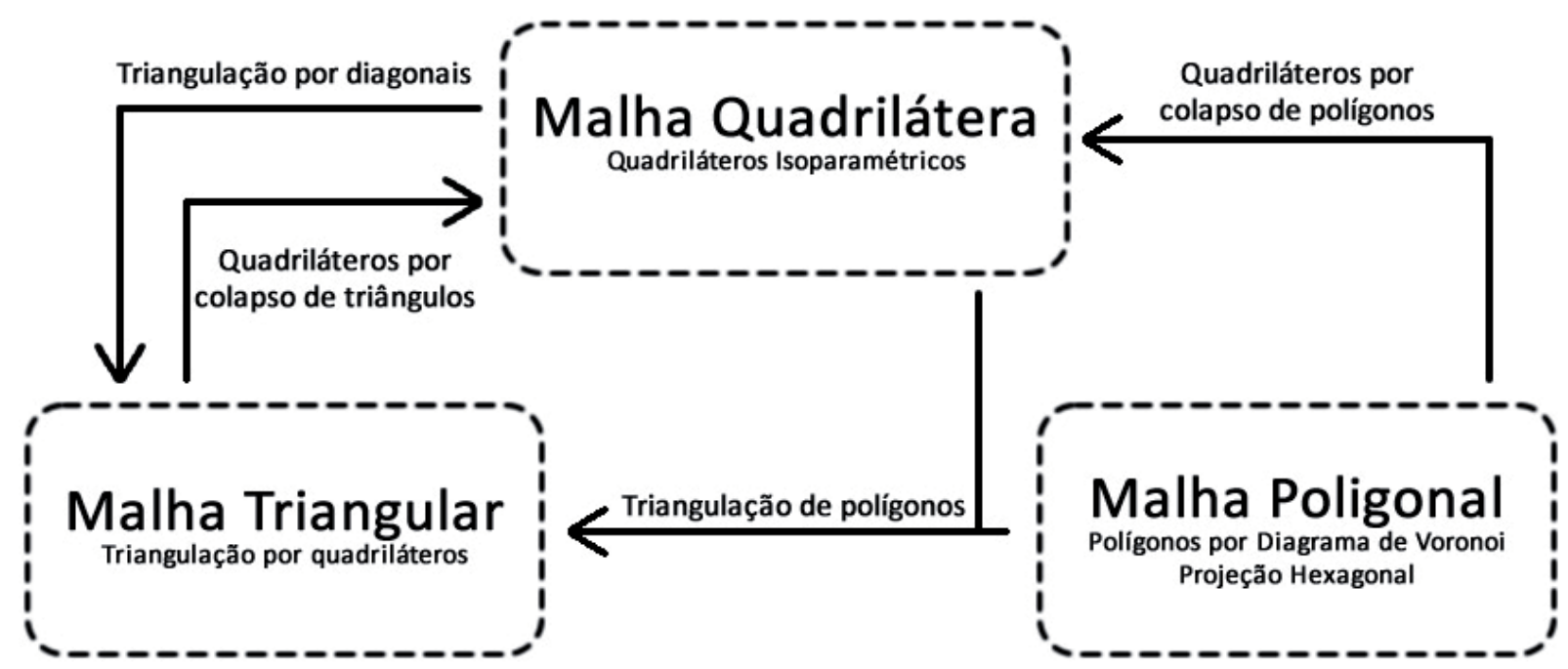

Figura 22 - Infográfico de tipos e modificadores de malhas

Fonte: dos autores

Apesar de este processo poder fornecer uma malha mais complexa e, possivelmente, interessante, pode ocorrer um aumento no número de elementos de vedação adjacentes por vértice, resultando numa maior complexidade desse elemento de fixação. Por esse motivo, 
aconselha-se controlar o número desses elementos adjacentes, mantendo a complexidade do elemento de fixação em um nível aceitável.

\section{CONCLUSÃO}

Como visto, existem diversos tipos de subdivisões de superfícies com formas livres e métodos de modificação e de alteração de malha. Cada um destes apresenta características e influências nos processos de produção e montagem, bem como no resultado final. Na Tabela 1, essas características são apresentadas em formato resumido.

Tabela 1 - Tipos de subdivisão e métodos

\begin{tabular}{|c|c|c|c|c|c|c|}
\hline \begin{tabular}{|l} 
Categoria de \\
subdivisão
\end{tabular} & \multicolumn{2}{|c|}{$\begin{array}{l}\text { Métodos de } \\
\text { Subdivisão }\end{array}$} & $\begin{array}{c}\text { Tipo de } \\
\text { superfícies }\end{array}$ & $\begin{array}{l}\text { Curvatura } \\
\text { das placas }\end{array}$ & $\begin{array}{l}\text { Conexão } \\
\text { entre placas }\end{array}$ & $\begin{array}{l}\text { Fixação no } \\
\text { vértice }\end{array}$ \\
\hline \multirow{3}{*}{ Triangulação } & Quadri. & Isop. & \multirow{2}{*}{$\begin{array}{c}\text { Contínuas } \\
\text { Trimmed } \\
\text { Contínuas }\end{array}$} & \multirow{3}{*}{ Planas } & \multirow{3}{*}{$\begin{array}{l}\text { Ângulos } \\
\text { variáveis }\end{array}$} & \multirow{3}{*}{$\begin{array}{l}\text { Elementos } \\
\text { com ângulos } \\
\text { variáveis * }\end{array}$} \\
\hline & \multicolumn{2}{|c|}{$\begin{array}{c}\text { Delaunay } \\
\text { Bolhas }\end{array}$} & & & & \\
\hline & Polígonos & $\begin{array}{c}\text { Projeção } \\
\text { Intersecção }\end{array}$ & Trimmed & & & \\
\hline \multirow{4}{*}{$\begin{array}{c}\text { Subdivisão } \\
\text { por } \\
\text { quadriláteros }\end{array}$} & \multicolumn{2}{|c|}{ Isoparamétrica } & \multirow{3}{*}{ Contínuas } & $\begin{array}{c}\text { Dupla } \\
\text { curvatura }\end{array}$ & $\begin{array}{c}\text { Planas } \\
\text { (tangentes } \\
\text { coincidem) }\end{array}$ & $\begin{array}{l}\text { Elementos } \\
\text { planos } * *\end{array}$ \\
\hline & \multicolumn{2}{|c|}{ Faixas desenvolvíveis } & & Curvatura & Ângulos & Elementos \\
\hline & \multicolumn{2}{|c|}{ Faixas regradas } & & simples & variáveis & $\begin{array}{l}\text { com ângulos } \\
\text { variáveis } * *\end{array}$ \\
\hline & \multicolumn{2}{|c|}{ Colapso de polígonos } & Trimmed & $\begin{array}{c}\text { Dupla } \\
\text { curvatura }\end{array}$ & $\begin{array}{c}\text { Planas } \\
\text { (tangentes } \\
\text { coincidem) }\end{array}$ & $\begin{array}{l}\text { Elementos } \\
\text { planos } * *\end{array}$ \\
\hline \multirow{4}{*}{$\begin{array}{l}\text { Subdivisão } \\
\text { por } \\
\text { polígonos }\end{array}$} & \multicolumn{2}{|c|}{ Planos tangentes } & Contínuas & Planas & $\begin{array}{l}\text { Ângulos } \\
\text { variáveis }\end{array}$ & $\begin{array}{l}\text { Elementos } \\
\text { com ângulos }\end{array}$ \\
\hline & \multirow{2}{*}{ Poliedros } & Voronoi & \multirow{3}{*}{ Trimmed } & \multirow{3}{*}{$\begin{array}{c}\text { Dupla } \\
\text { curvatura }\end{array}$} & \multirow{3}{*}{$\begin{array}{c}\text { Planas } \\
\text { (tangentes } \\
\text { coincidem) }\end{array}$} & \multirow{3}{*}{$\begin{array}{l}\text { Elementos } \\
\text { planos *** }\end{array}$} \\
\hline & & Hexágonos & & & & \\
\hline & \multicolumn{2}{|c|}{ Projeção } & & & & \\
\hline
\end{tabular}

* Manter, no máximo, seis elementos por vértice;

** Manter, no máximo, quatro elementos por vértice;

*** Manter, no máximo, três elementos por vértice.

A decisão pelo tipo de subdivisão se dará por questões estéticas, de custos, de materiais, funcionais, de intenção do arquiteto e outras. Toda obra possui limitações de custos, sendo este um importante fator a ser levado em conta. Qualquer edifício cuja forma ou método construtivo saia do tradicional tende a ter um custo relativamente maior, em consequência do nível de especialização necessária para sua realização. Contudo decisões de projeto podem reduzir esses custos e viabilizar a obra.

Ao se trabalhar, por exemplo, com painéis de alumínio composto (ACM), pode-se facilmente efetuar curvaturas simples sem grandes custos, porém esse material costuma não suportar duplas curvaturas de raios pequenos. No caso de chapas metálicas, é possível moldá-las a quente ou curvá-las a frio, dependendo da curvatura desejada, além de permitir o uso de soldas, que podem criar uma maior ilusão de continuidade. Já no caso do vidro (que é o elemento translúcido 
mais utilizado) só a questão de curvatura já pode inviabilizar um edifício, preferindo-se utilizar, ao máximo, peças que possam ser curvadas a frio na obra e com curvatura simples. Segundo o arquiteto Neil Katz ${ }^{7}$, que possui vasta experiência com fachadas envidraçadas, até a simples mudança do tipo de vidro, para um que tenha uma maior flexibilidade, já viabilizou algumas obras do escritório SOM, por reduzir significativamente o uso de vidros curvados a quente.

O controle preciso das técnicas de subdivisão de superfícies é importante não apenas por motivos estéticos e de necessidade de limitação do tamanho das peças; ele também pode ser decisivo na viabilização de uma obra. Nas obras de maior complexidade são aplicados métodos para modificar a subdivisão da superfície, aumentando o número de placas com curvatura simples (que são produzidas por calandras de controle numérico) e reduzindo ao máximo as de curvatura dupla, que exigem a produção de moldes fresados, sendo mais caras de produzir. Esse processo é chamadao de racionalização. Contudo, tendo em vista o desenvolvimento recente de novos métodos de produção de superfícies de dupla curvatura, em especial os moldes flexíveis formados por pinos controlados por computador (multi-point-stretch-forming), esse pode deixar de ser um problema.

É importante ressaltar que, quando se utiliza qualquer subdivisão que gere placas planas, existem problemas relacionados às conexões e fixações dessas placas que precisarão ser solucionados durante o projeto. Por outro lado, ao se utilizar placas de dupla curvatura, essas questões são resolvidas de modo mais fácil, surgindo, por outro lado, a questão do método de curvatura do material.

Concluindo, podem-se ver como todos esses fatores são fundamentais no resultado final do edifício, tanto no que diz respeito à viabilização quanto às questões estéticas. Sendo a subdivisão da forma tão influente, é importante conhecer seus métodos e características, visando à sua aplicação nos mais diversos projetos.

\section{CONSIDERAÇÕES FINAIS}

Neste trabalho, buscou-se descrever os principais métodos de subdivisão de formas livres, a partir da revisão da literatura recente e de uma entrevista com um especialista. Contudo, como não existe uma única forma de subdividir toda e qualquer forma livre (WANG, 2013), é possível que os métodos aqui apresentados não sejam adequados para algumas formas em particular. Dependendo da complexidade da forma, é possível que seja necessário separá-la em subsuperfícies, subdividindo cada uma separadamente.

Além disso, devem-se ter alguns cuidados na criação da forma livre propriamente dita, evitando, por exemplo, regiões côncavas na parte superior, que poderiam acumular água. Curvas com raios pequenos também são desaconselhadas, pois as faces podem sofrer deformações durante o processo de subdivisão, e o material pode não permitir uma curvatura tão acentuada, ou serão necessários elementos muito pequenos para seguir a forma original.

No que diz respeito às quantidade de placas adjacentes a cada vértice, foram fornecidos números de base para se evitar uma grande complexidade da peça. Porém essa quantidade pode ser alterada, podendo ser viável a construção de elementos mais complexos dependendo da tecnologia utilizada.

\footnotetext{
${ }^{7}$ Entrevista concedida pelo arquiteto Neil Katz, do escritório de arquitetura SOM, Chicago (EUA), a Filipe Campos, em 12/03/2016.
} 


\section{REFERÊNCIAS}

BERG, M.; CHEONG, O.; KREVELD, M.; OVERMARS, M. Computational geometry: algorithms and applications. 3. ed. Berlin: Springer, 2008.

BURRY, J.; BURRY, M. The New Mathematics of Architecture. Londres: Thames \& Hudson, 2010.

CANEPARO, L. Digital fabrication in architecture, engineering and construction. Torino, Itália: Springer, 2014.

CUTLER, B.; WHITING, E. Constrained planar remeshing for architecture. 2007. Disponível em: <https:// www.cs.rpi.edu/ cutler/publications/planar_remeshing_gi07.pdf>.

HAGER, I.; GOLONKA, A.; PUTANOWICZ, R. 3D printing of buildings and buildings components as the future of sustainable construction? Procedia Engineering, n. 151, p. 292-299, dez. 2016.

HANSMEYER, M.; DILLENBURGER, B. Mesh grammars: procedural articulation of form. 2013. Disponível em: <http://papers.cumincad.org/data/works/att/caadria2013_259.content.pdf>.

KOLAREVIC, B. Architecture in the digital age: design and manufacturing. 1. ed. Londres: Spon Press, 2005. POTTMANN, H.; ASPERL, A.; HOFER, M.; KILIAN, A. Architectural Geometry. 1. ed. Exton, PA: Bentley Institute Press, 2007.

POTTMANN, H.; SCHIFTNER, A.; WALLNER, J. Geometry of architectural freeform structures. Internationale Mathematische Nachrichten, n. 209, p. 15-28, 2008.

SHIMADA, K.; GOSSARD, D. Bubble Mesh: automated triangular meshing of nonmanifold geometry by sphere packing. ACM Third Symposium on Solid Modeling and Applications, 1995. Disponível em: <http:// citeseerx.ist.psu.edu/viewdoc/summary?doi=10.1.1.49.9457>.

SURAZHSKY, V.; ALLIENZ, P.; GOTSMAN, C. Isotropic remeshing of surface: a local parameterization approach. Research Report-4967, INRIA, 2003. Disponível em: <https://hal.inria.fr/inria-00071612/document>.

TREVISAN, C. Per la storia della stereotomia: geometrie, metodi e costruzioni. Roma: Aracne Editrice, 2011.

WANG, T. H. Tesselating freeform surfaces with boundary-driven analysis. 2013. Disponível em: <http:// papers.cumincad.org/data/works/att/caadria2013_156.content.pdf>.

WELCH, W.; WITKIN, A. Free-form shape design using triangulated surfaces. 1994. Disponível em: <http:// dl.acm.org/citation.cfm?doid=192161.192216 >.

\section{Sobre os autores:}

Filipe Medeia de Campos: Arquiteto e urbanista formado pela Universidade Estadual de Campinas (UNICAMP).E-mail:f_m_campos@yahoo.com.br

Gabriela Celani: Arquiteta e mestre pela FAU-USP e PhD pelo MIT, onde foi orientanda e assistente de pesquisa e de ensino de William Mitchell e de Terry Knight. É também livre-docente pela Unicamp e pós-doutora pela Universidade Técnica de Lisboa, onde atuou como docente junto ao prof. José Pinto Duarte. Desde 2004 é pesquisadora e docente do curso de Arquitetura e Urbanismo da Unicamp, onde criou o Laboratório de Automação e Prototipagem para Arquitetura e Construção (LAPAC) e o grupo de pesquisas Teorias e Tecnologias Contemporâneas Aplicadas ao Projeto. Universidade Estadual de Campinas (UNICAMP). E-mail: celani@fec.unicamp.br 